\title{
Employee Compensation and Benefits: Case Study on Presidency College, Bangalore
}

\author{
Badri HS*
}

\section{Abstract}

Company/Institution's achievements are decided in large part by the compensation and benefit plans. Compensation and benefits have a major role to play in the decision-making process of job seekers. Compensation involves how employees are paid, hourly or salary, and benefits involve the type of medical insurance, annual $\mathrm{PhD}$ allowance, annual performance incentive pay of up to a month's salary and retirement benefits. Providing benefits to their employees is one way in which organizations typically maximize productivity in their business practices. Candidates with excellent talent and experience, which can give the much needed competitive advantage to the company, are usually attracted by the benefits that a company offers. Also, compensation and benefits could be used as a measurement tool for the effects of productivity, company growth, and success. Compensation and benefits could also impact the recruitment and retention of labor to a large extent. The allusion of the plan is for workers to believe the compensation plan is reasonable and fair (Cascio, 2010). Managers should incorporate cross-training to engage employees to excel in performing their job duties at the highest levels for the best outcome (Cascio, 2010).

\footnotetext{
*Presidency College, Bengaluru, India; badrihs@presidency.edu.in
} 
Keywords: Compensation, Benefits, Productivity, Potential, Success

\section{Introduction}

Compensation is a major factor in job quality, although it is not regarded as the most important. While most organizations can consider the possibility of offering competitive salary and benefits to attract and employ the best staff, organizations which work on not-for-profit model have a few distinct challenges. Organizations can, and should, market their strengths because people are also looking for jobs that make a difference, offer interesting and varied challenges and have positive working relationships.

To increase the engagement of executives on organizational goals and compensate them upon achieving such goals, many for-profit and a few non-profit organizations use incentive compensation. In a non-profit mission-based context the concept of incentive pay could not be easily adapted as it is often considered synonymous with rewarding employees for making the for-profit organization more money. However, research shows that the use of incentive pay may be increasing among non-profits.

As the struggle for optimum use of resources by the non-profits, "pay-for-performance" is becoming an enticing option. If structured appropriately, Incentive pay, if planned properly, could be an invaluable tool providing executives with a sharp focus on achieving organizational goals and objectives. If the organization is successful, executives are rewarded and incentivized to continue performing; if performance is sub-par, compensation costs for the organization will go down.

It is of prime importance for organizations/institutions to enforce scientifically designed realistic reward systems aligned with annual work plan/goal and other Institutional management / development activities to enrich staff effectiveness and efficiency and to attract and retain the best staff talent.

The aim of this paper is to examine developments on the type and amount of compensation necessary to attract technically and culturally qualified staff members. 


\section{Picking the "Right" Metrics}

It is important to take stock of design considerations when starting a successful incentive plan, like all other compensation programs. One of the important and challenging tasks is to determine suitable performance metrics. The right metrics can provide focus, help strengthen the organization financially, and encourage desirable behaviors and outcomes. The wrong metrics can devastate and undermine the mission and create conflicts of interest, real or perceived, between organizational interests and those of executives.

Chhippa (2009) showed that human resources can be influenced by appraisal, compensation and benefits which is the key to improve the effectiveness and accountability in higher education institutions.

It would be beneficial if the "right" quantifiable metrics is already embedded in the organization's mission. Also, the selected metrics must be quantifiable and ones those executives can reasonably influence.

However, the amount of performance metrics varies based on the facts and circumstances of the organization. Performance targets are usually determined when performance metrics are selected. Performance will be assessed based on the targets set as a benchmark. It is advised that the performance metrics and targets should be meaningful, measurable and achievable to be successful.

It is often helpful to establish a range of performance levels of achievement, typically defined as threshold/minimum, target and maximum. For performance below threshold, no incentive compensation is earned; however, as performance surpasses threshold levels, greater awards are earned, until the maximum performance level is achieved. Performance above maximum often does not warrant additional payout. Capping the upside of incentive compensation and restricting pay for performance below threshold will both help reduce financial risk (particularly with respect to maximum payouts), send a strong message regarding linkage between pay and performance and ensure a clear understanding of the goals within and outside of the organization. 


\section{Compensation and Benefits-Employer Challenges}

- Employee benefit packages need to designed in a way that meets the needs of a diverse workforce

- Helping existing employees understanding the "value" of their benefits and compensation

- Administering benefit programs is a costly and timeconsuming effort and not a immediately profit-making venture

- Continued rising health care costs

- Limited budgets (sometimes benefits average $25 \%-40 \%$ of payroll in most organizations)

- Government restrictions/legislation/public policy

\section{Performance Appraisal, Compensation and Benefits in Higher Education: Existing System}

One of the important mechanisms for policymakers' efforts to exercise control over productivity in higher education is to place a greater emphasis on accountability. An effective performance appraisal system is one of many methods that are useful for assessing and improving productivity (Mani, 2002). Outside requests for accountability have led to a greater importance being placed on the evaluation of outputs and formal assessment (Austin \& Gamson 1983); Blackburn \& Pitney, (1988)). Although various researchers have noted the widespread use of performance appraisal in organizations, the use of the same in higher education in India has not been documented in detail.

In the arena of higher education, there has been considerable research done in the area of performance evaluation of faculty. However, little research exists on the assessment of staff performance (Seldin, 1988). Higher education has devoted little effort to appraisal and climate surveys for administrative personnel (Cox \& Downey, 2002). Winston and Creamer (1997) stated that in most colleges and universities, employees report that performance appraisal is a weakness in the overall employment practices. 
Evaluation is becoming a significantly more important instrument for policymakers' efforts to implement control over higher education productivity, but there is little empirical work on the performance and effectiveness of higher education administrative employees who contribute to this productivity (Heck et al., 2000).

The common parameters used by most of the Higher Educational Institutions for Performance appraisal are:

a) Annual confidential/performance reports of teachers by supervisory level

b) Lesson observation

c) Performance appraisal by students

d) Performance appraisal based on results

e) Performance appraisal by Principal

f) Performance appraisal by HODs

The common benefits provided by most of the Higher Educational Institutions are:

i. PF, Gratuity - As per Norms

ii. Paid Vacation Leaves

The existing system of performance appraisal of faculty in most HEIs has following deficiencies:

i. Lack of transparency and objectivity

ii. Inadequate participation of the faculty in designing the performance appraisal system

iii. Absence of discussion between Head of the Institution or Head of the Department with the faculty regarding the target to be achieved and his/her actual performance

Further the documentation on teacher performance system in private unaided HEIs which now constitute over $50 \%$ is also not readily available. Thus there is a need to develop an overall 
framework and guiding principles governing teacher performance and teacher audit.

New System of Performance Appraisal, Compensation and Benefits Proposed and Practiced

The following key areas and performance indicators, compensation and benefits are proposed in the new performance appraisal system. The indicators are rated on a scale of [1-5] as follows based on overall aggregate rating

Overall aggregate rating [50-60]: 1-Under Performance

Overall aggregate rating [60-70]: 2-Performance Requires Improvement

Overall aggregate rating [70-80]: 3-Acceptable Performance

Overall aggregate rating [80-90]: 4-Very Good Performance

Overall aggregate rating [90-100]:5-Exceptional Performance

Compensation and Benefits at Presidency College:

- Pension Benefits through Life Insurance Corporation of India

- Loan Facility

- Achiever $100 \%$ Result

- 2 Days paid leave in a month for Ph.D. pursuing staff

- Annual Performance Incentive pay of up to a month's salary.

- Employment Provident Fund \& Gratuity

- Medical Insurance: Teaching and Non-Teaching for Rs. 1,00,000/-

- Employee Contribution: Rs. 1200/-

- Employer Contribution: Rs. 1200/-

- Encashment of Earned Leave

- Special Pay to Staff Members for Continuous Service

- Higher increments for those who perform well

- Laptops issued to all Faculty members while at service

- Faculty members are encouraged to take up consultancy, projects and research work. 
- Faculty members are sponsored to

- Pursue further studies

- Present papers in conferences abroad periodically.

Impact of New System of Performance Appraisal, Compensation and Benefits

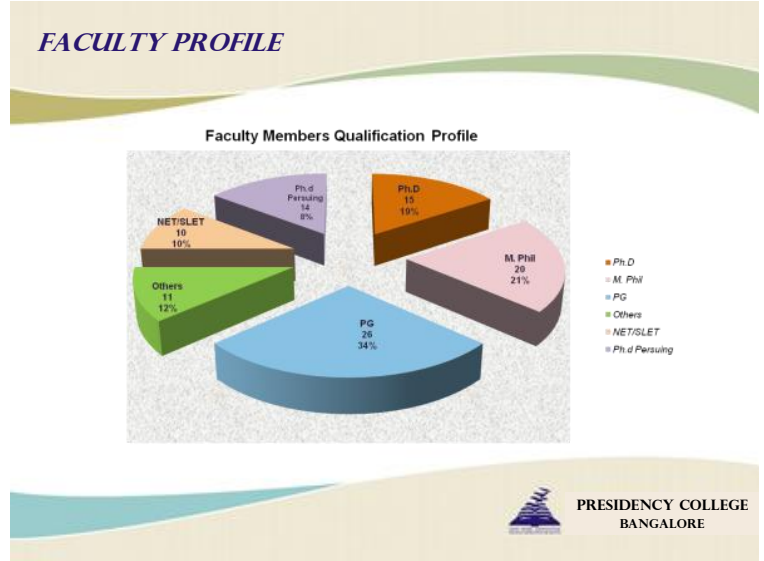

Fig 1.1 The Faculty Profile

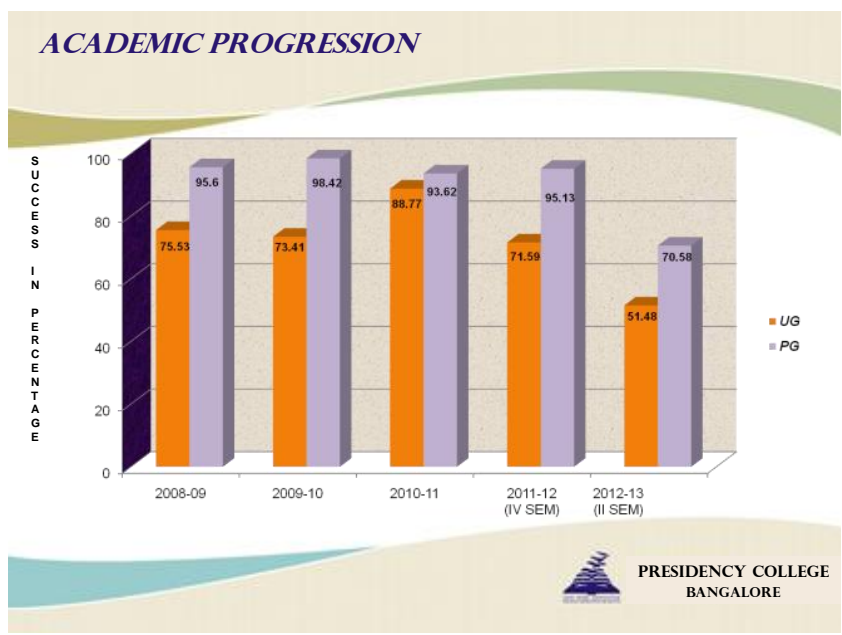

Fig 1.2 The Academic Progression 


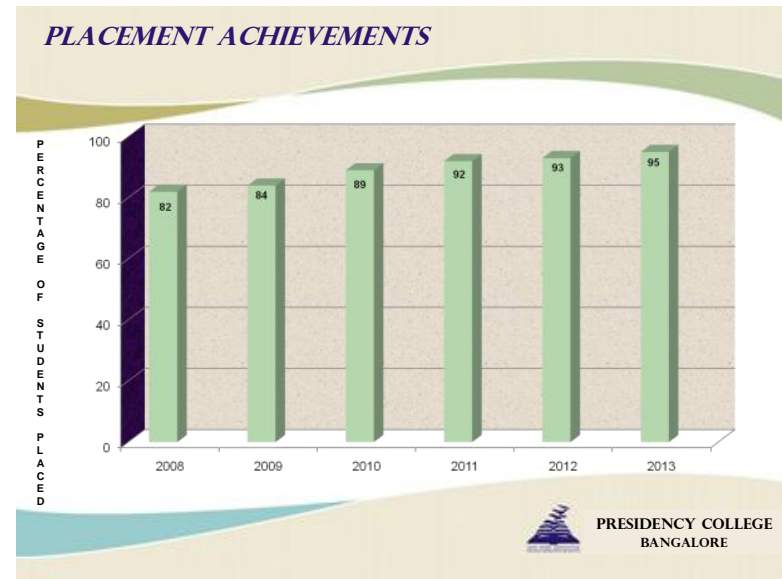

Fig1.3 The Placements Achievements [in \%]

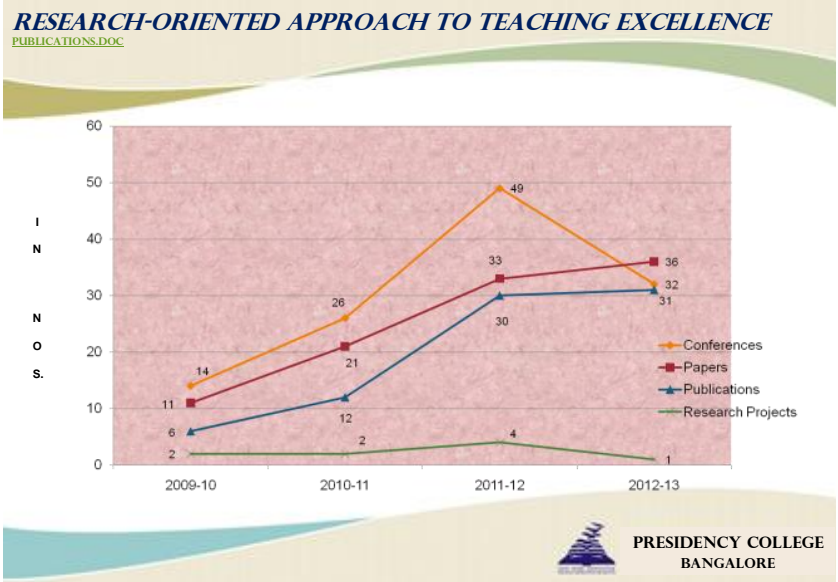

Fig 1.4 The Research Oriented Approach to Teaching Excellence 


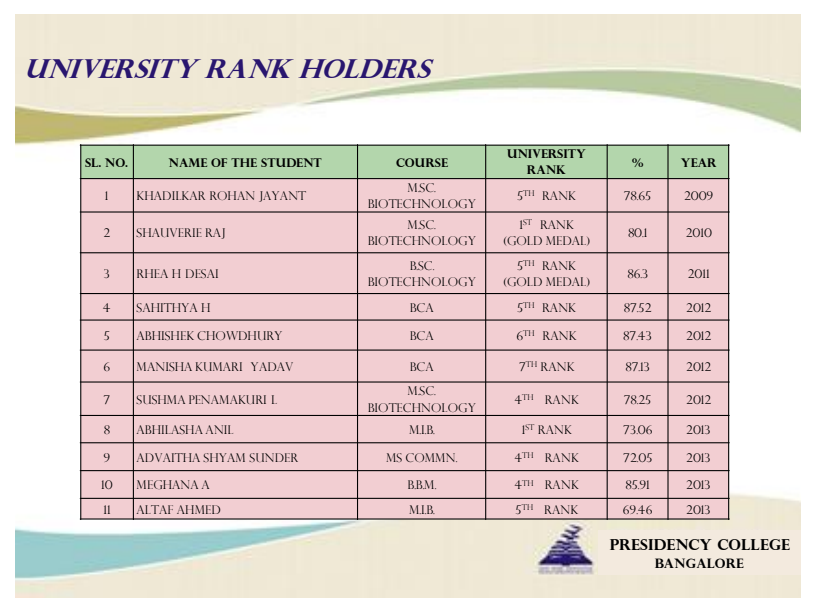

Fig 1.5 The University Rank Holders

\section{Conclusions}

In conclusion, this paper attempts to provide a conceptual framework for developing well structured new system of performance appraisal, compensation and benefits plan for faculty members of Higher Educational Institutions in order to enhance overall holistic developments/improvements in academics standards, co-curricular and extra-curricular activities, students' performance and research standards.

\section{References}

Austin, A. E., \& Gamson, Z. F. (1983). Academic workplace: New demands, heightened tensions. ASHE-ERIC Higher Education Research Report No. 10. Washington, DC.: Association for the Study of Higher Education.

Beena.S. (2010). Foreign Education providers in India: Genesis, Actions and Reactions. University news, 48(37), 21-29

Boswell, W. R., \& Boudreau, J. W. (2000). Employee satisfaction with performance appraisals and appraisers: The role of perceived appraisal use. Human Resource Development Quarterly, 11(3), 283-299. 
Brinkerhoff, D. W., \& Kanter, R. M. (1980). Appraising the performance of performance appraisal. Sloan Management Review, 21(3), 3-16.

Chhipa R.C. (2009). To increase technical manpower through performance appraisal in Indian Universities and higher educational institutions.

Cox, K. S., \& Downey, R. G. (2002). Resurgence of administrative evaluations and unit climate surveys to improve and strengthen institutional leadership. AIR 2002 Forum Paper

Fletcher, C. (2001). Performance appraisal and management: The developing research agenda. Journal of Occupational $\mathcal{E}$ Organizational Psychology, 74(4), 473.

Grote, R. C. (2002). The performance appraisal question and answer book: A survival guide for managers. New York: American Management Association.

Heck, R. H., Johnsrud, L. K., \& Rosser, V. J. (2000). Administrative effectiveness in higher education: Improving assessment procedures. Research in Higher Education, 41(6), 663-684.

McKinnon, N. C. (1993). Development of a performance appraisal program for nonacademic staff at Atlantic Baptist College.

P. Senthil Kumar, Dr. D. Brahadeeswaran (2011). Performance Appraisal of Faculty in Higher Educational Institutions in India. Amet Journal, 27-32.

Rynes, S. L., Gerhart, B., \& Parks, L. (2005). Personnel psychology: Performance evaluation and pay for performance. Annual Review of Psychology, 56(1), 571-600. 